\title{
DEGRADATION OF SPERMATOZOA IN THE EPIDIDYMIS OF A SEASONALLY BREEDING MAMMAL, THE ROCK HYRAX, PROCAVIA CAPENSIS
}

\author{
R. P. MILLAR* \\ Unit of Reproductive Biology, University of Liverpool, \\ Life Sciences Building, P.O. Box 147, Liverpool L69 3BX \\ (Received 4th November 1971, accepted 24th April 1972)
}

Several authors have observed that the incidence of dead and decapitate spermatozoa in the more proximal regions of the epididymis is higher than in the cauda epididymidis and ductus deferens (see Glover, 1961; Roussel, Stallcup \& Austin, 1967). These findings suggest that, if spermatozoa die during transit through the epididymis, they are removed from the lumen of the duct before they reach the cauda epididymidis. There has been considerable speculation as to how this might be achieved, and entry of spermatozoa into the epididymal epithelium has been reported (Phadke, 1964; Nicander, 1965; Crabo, Gustafsson, Nicander \& Rao, 1971), while ingestion of supposedly dead spermatozoa by macrophages ('spermiophages') has also been described (Phadke \& Phadke, 1961; Phadke, 1964, Roussel et al., 1967). In normal circumstances, relatively few macrophages are seen in mammalian epididymides, but then only a small proportion of the sperm population will need to be removed. In experimental conditions, however, such as artificial cryptorchidism or ligation of the epididymis, a high percentage of spermatozoa rapidly die and many are completely eliminated from the lumen of the body of the epididymis (Glover, 1962, 1968). The removal of these spermatozoa is too striking to be accounted for by the relatively few macrophages that are seen in the area, and the possibility of lysis or autolysis of spermatozoa presents itself as an alternative mode of elimination. Evidence for the occurrence of sperm degradation in the epididymis of the rock hyrax is reported here from observations that arose during a wider study of the testis and epididymis in this species.

During the period of testicular activity of Procavia capensis in South Africa, which lasts from February to April (Millar \& Glover, 1970), sperm smears were prepared by making incisions in the caput and cauda epididymidis and then lightly drawing the tissue across glass slides. After drying in air, the smears were fixed in acetone at $5^{\circ} \mathrm{C}$ for $30 \mathrm{~min}$. Some smears were stained by the method of Papanicolaou (1942) and others with haematoxylin and by the periodic acidSchiff (PAS) method, in order to show up the acrosome.

Both staining methods revealed that, besides containing normal spermatozoa, the epididymal lumen, particularly in the caput epididymidis, contained some spermatozoa with distinctly expanded heads (PI. 1, Fig. 1). The degree of expansion varied, suggesting a process of degradation, which was characterized

* Present address: Department of Chemical Pathology, Medical School, University of Cape Town, South Africa. 
by a progressive expansion of the sperm heads. This possibility was supported by the presence of even larger basiphilic bodies, which appeared to represent a later stage of degradation following expansion of the sperm head (Pl. 1, Fig. 2). Staining with PAS indicated that these basiphilic bodies were derived from spermatozoa since an acrosome could be seen at their surface (Pl. 1, Fig. 2). However, not all basiphilic bodies found in the epididymis are necessarily derived from spermatozoa because spermatids, prematurely released from the seminiferous tubules, were also seen undergoing a similar process of expansion and dissolution in the caput epididymidis. These were recognized by a characteristic bleb or knob on the acrosome (Pl. 1, Figs 2 and 3). Thus, the incidence of basiphilic bodies in the caput epididymidis appears to represent the sum total of the degradation of all defective products of spermatogenesis.

\section{TABLE 1}

PERGENTAGE OF SPERMATOZOA WITH EXPANDED HEADS IN SMEARS TAKEN FROM THE CAPUT AND CAUDA EPIDIDYMIDIS DURING VARIOUS PHASES OF THE TESTIS CYGLE*

\begin{tabular}{|c|c|c|c|}
\hline \multirow[b]{2}{*}{ Date } & \multirow{2}{*}{$\begin{array}{l}\text { No. of } \\
\text { animals }\end{array}$} & \multicolumn{2}{|c|}{$\%$ spermatozoa with expanded heads } \\
\hline & & $\begin{array}{c}\text { Caput } \\
\text { epididymidis } \\
\pm S . E .\end{array}$ & $\begin{array}{l}\text { Cauda } \\
\text { epididymidis } \\
\pm S . E .\end{array}$ \\
\hline $\begin{array}{l}\text { 10th February } \\
\text { 3rd March } \\
\text { 19th March } \\
\text { 14th April } \\
\text { 22nd May }\end{array}$ & $\begin{array}{l}4 \\
3 \\
3 \\
3 \\
3\end{array}$ & $\begin{array}{r}77 \cdot 7 \pm 12 \cdot 1 \\
27 \cdot 1 \pm 18 \cdot 5 \\
3 \cdot 1 \pm 1 \cdot 0 \\
3 \cdot 6 \pm 1 \cdot 1 \\
82 \cdot 0 \pm 14 \cdot 7\end{array}$ & $\begin{array}{c}37.4 \pm 15.1 \\
2.2 \pm 1.7 \\
5.7 \pm 1.7 \\
0.0 \pm 0.0 \\
.9 .9 \pm 3.1 \dagger\end{array}$ \\
\hline
\end{tabular}

* No spermatozoa were to be found in the epididymis during the period from June to January.

$\dagger$ Of the remaining spermatozoa, $42 \%$ showed signs of disintegration without enlargement of the head.

It seems unlikely that expansion of the sperm heads was produced artificially by the fixation and staining procedures because these forms were also seen in nigrosin-eosin smears. Moreover, when spermatozoa taken from various levels of the epididymis of normal rabbits were also subjected to these procedures, none with enlarged heads were to be seen.

The number of basiphilic bodies and expanded sperm heads was highest in the caput epididymidis at the beginning (February) and end (May) of the testicular cycle (Table 1). But in corresponding months, their occurrence was much lower in the cauda epididymidis (Table 1), and in April, when the majority of copulations occurred, spermatozoa with expanded heads were seldom seen in this region. This suggests that degradation of most of the defective spermatozoa is accomplished before the main mass of spermatozoa reaches the cauda epididymidis and also indicates that when the remaining spermatozoa mature, they become resistant to a process of degradation that involves expansion of the head. When their elimination becomes necessary at the end of the mating season, they are degraded in a different way. It has long been known that the maturation of spermatozoa is accompanied by changes 

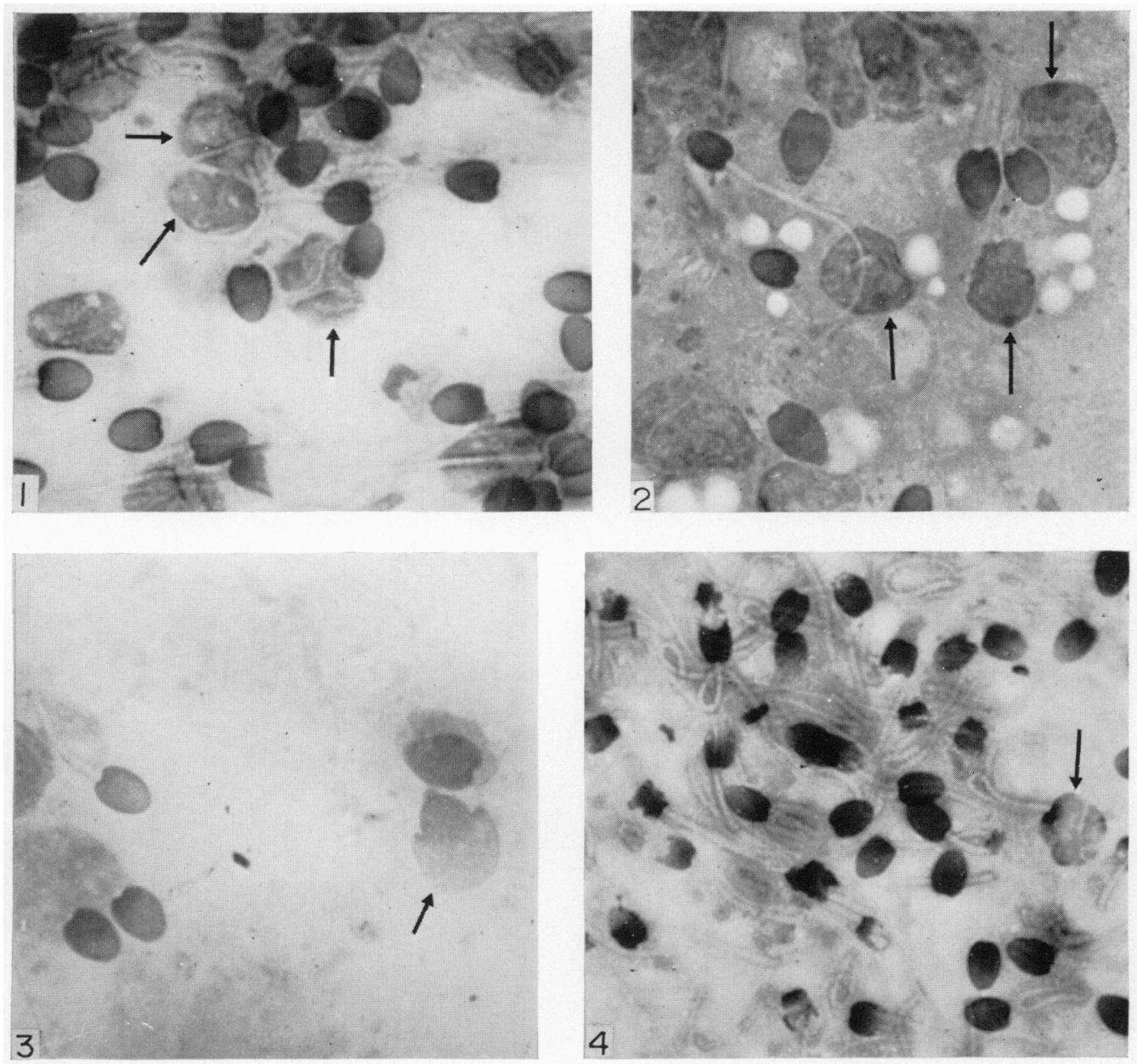

FIG. 1. Spermatozoa taken from the caput epididymidis of a rock hyrax in May, showing normal spermatozoa and others with expanded heads. Spermatozoa with expanded heads are usually tailless and difficult to identify, but three spermatozoa which have retained the mid-piece and tail are shown (arrowed).

Fig. 2. Sperm smear taken from the caput epididymidis of a rock hyrax in February, showing mainly degrading spermatids with characteristic 'blebbed' acrosomes but also some basiphilic bodies representing degraded spermatozoa with acrosomes (arrowed).

Fic. 3. Same as for Fig. 4, but showing a single spermatid ('blebbed' acrosome) with the posterior half of the nucleus expanded and vesiculated (arrowed).

Fig. 4. Spermatozoa taken from the cauda epididymidis of a rock hyrax in May, showing the majority of spermatozoa degrading without prior expansion of the head. Note the appearance of two clear lateral spots in the nuclei of some spermatozoa, followed by vesiculation, and finally complete disruption of the nucleus in the acrosomal region. $\Lambda$ single spermatozoon with the head expanded is also shown (arrowed). All spermatozoa stained with PAS and haematoxylin. $\times 1250$. 
in the cell membrane, and recently Calvin \& Bedford (1971) have also demonstrated nuclear changes. They found that, when spermatozoa taken from the caput epididymidis of a variety of eutherian mammals were incubated in a sodium borate/dithiothreitol medium, their nuclei became swollen and decondensed more rapidly than those of mature spermatozoa from the cauda epididymidis. Thus, it is not surprising that at the end of the mating season (May) in the hyrax, only $9.9 \%$ of spermatozoa in the cauda epididymidis were seen to be undergoing degradation through expansion of the head, while $42 \%$ showed signs of degradation without prior expansion of the head (Pl. 1, Fig. 4; Table 1). It is likely, therefore, that the increased numbers of spermatozoa with expanded heads found in the cauda epididymidis at the beginning and end of the mating season had come from the upper levels of the epididymis. Certainly, the chances of such disintegrating forms reaching the cauda are greater at these times of the season because of their very high incidence in the head of the epididymis.

The increased occurrence of degraded spermatozoa at the two extremes of the mating season emphasizes the dependence of epididymal function on testicular hormones for the maintenance of the viability of spermatozoa, and it is interesting that, during these phases of diminished androgen production, the activity of acid and alkaline phosphatase in the epithelial cells lining the duct is markedly reduced ( $R$. P. Millar, unpublished data). This suggests that the degradation of spermatozoa under these circumstances may be brought about by changes in the composition of the fluid in the epididymal lumen. If such changes occur, it remains to be learned whether they are directly responsible for the degradation of the spermatozoa or only serve to induce autolysis.

It is suggested that, in the rock hyrax, defective spermatozoa are degraded in the caput epididymidis and are mostly eliminated before they reach the cauda epididymidis. At the end of the mating season, unwanted mature spermatozoa in the cauda epididymidis are also degraded but in rather a different manner. It is, therefore, apparent that in the hyrax, spontaneous degradation and lysis rather than classical phagocytosis are the primary means of elimination of defective or unwanted spermatozoa from the lumen of the epididymis.

The Department of Nature Conservation (Cape) was responsible for financial support during the collection of material in South Africa, and tenure of a Beit Fellowship supported the research in Liverpool. The Ford Foundation provided finance for laboratory expenses. Dr T. D. Glover's help, encouragement and advice in preparing this manuscript and Mr P. A. Racey's helpful comments are gratefully acknowledged.

\section{REFERENCES}

CALvin, H. I. \& BEDFoRd, J. M. (1971) Formation of disulphide bonds in the nucleus and accessory structures of mammalian spermatozoa during maturation in the epididymis. F. Reprod. Fert. Suppl. 13, 65.

Grabo, B., Gustafsson, B., Nigander, L. \& Rao, A. R. (1971) Subnormal testicular function in a bull concealed by phagocytosis of abnormal spermatozoa in the efferent ductules. F. Reprod. Fert. 26, 393.

GLover, T. D. (1961) Disintegrated spermatozoa from the epididymis. Nature, Lond. 190, 185. 
GLover, T. D. (1962) The response of rabbit spermatozoa to artificial cryptorchidism and ligation of the epididymis. F. Endocr. 23, 317.

Glover, T. D. (1968) Some aspects of function in the epididymis; experimental occlusion of the epididymis in the rabbit. Int. F. Fert. 14, 215.

Millar, R. P. \& Glover, T. D. (1970) Seasonal changes in the reproductive tract of the male rock hyrax, Procavia capensis. F. Reprod. Fert. 23, 497.

NiCANDER, L. (1965) An electron microscopical study of absorbing cells in the posterior caput epididymidis of rabbits. Z. Zellforsch. mikrosk. Anat. 66, 829.

Papanicolaou, G. N. (1942) A new procedure for staining vaginal smears. Science, $\mathcal{N} . X .95,438$.

PhADKe, A. M. (1964) Fate of spermatozoa in cases of obstructive azoospermia and after ligation of vas deferens in man. 7. Reprod. Fert. 7, 1.

Phadke, A. M. \& Phadke, G. M. (1961) Occurrence of macrophage cells in the semen and in the epididymis in cases of male infertility. F. Reprod. Fert. 2, 400.

Roussel, J. D., Stallcup, O. T. \& Austin, L. R. (1967) Selective phagocytosis of spermatozoa in the epididymis of bulls, rabbits, and monkeys. Fert. Steril. 17, 509. 